\title{
The Taboo Love: Male-Male Erotica as a Potential Sexual Attraction for girls Regulate the Brain Response
}

Xiaowei Jiang ${ }^{3}, \mathrm{Na} \mathrm{Ao}^{1}$, Yingying $\mathrm{Chen}^{1}$, Huihui Niu ${ }^{1}$, Yanan Chen, Ph.D ${ }^{1,2^{*}}$, Chenghao Zhou ${ }^{1}$, Feng Du ${ }^{4}$

1 Institute of Psychology and Behavior, Henan University, Kaifeng, China 2 Institute of Cognition, Brain and Health, Henan University, Kaifeng, China

3 Department of Bioengineering, University of Pennsylvania, Philadelphia, PA, United States Address

4 Institute of Psychology, Chinese Academy of Sciences, Beijing, China

correspondence to:

Yanan Chen

Institute of Psychology and Behavior, Henan University, Kaifeng, China

Institute of Cognition, Brain and Health, Henan University, Kaifeng, China

85 Minglun Street, Kaifeng, Henan, China, 475001

E-mail: chenyn@ henu.edu.cn

\section{Declarations}

Funding: This research was supported by Institute of Psychology, CAS (No.GJ202007).

Ethical Approval: All procedures performed in studies involving human participants were in accordance.

Data Availability: Because personal privacy is involved and some of the subjects do not want their options to be actively disclosed. All data, scripts, and images in the present study are available to require. 
Contribution: XJ and NA contributed equally. Yingying C and HN contributed equally. NA raised this issue. XJ drafted the paper and analyzed the data. NA, XJ, FD, and Yanan C revised the paper. Yingying $\mathrm{C}$ and $\mathrm{HN}$ collected the data. CZ did the data entry. 


\section{The Taboo Love: Male-Male Erotica as a Potential Sexual Attraction for girls Regulate the Brain Response}




\begin{abstract}
Female-oriented male-male erotica is defined as commercial and fan-created media that thematically focuses on romantic love and pornography between two men. Despite the widespread popularity of this subculture, there is a lack of empirical studies on the neural mechanism for enjoying male-male erotica using reliable research methods. The present study focuses on this special female colony, aimed to use functional nearinfrared spectroscopy (fNIRS) to explore the neural and behavioral mechanisms exhibited by male-male erotica fans when they are viewing homosexual men images. Results indicated that most girls indulge in male-male erotica productions at puberty. Funs response faster and showed higher accuracy than nonfans to homosexual men stimuli. Furthermore, funs showed a much greater brain response in PFC than nonfans to homosexual men stimuli than to heterosexual stimuli. The wider response in PFC, which was referred to motivational drives including reward-seeking contributes to compulsive addictive behaviors. Our results speculate that the male-male erotica funs' neural and behavioral mechanisms to homosexual men images are more specific than nonfans'. These results embodied a stable but taboo sexual attraction for girls, which should be paid high attention to by educational institutions, to properly guide female sex education and school education.
\end{abstract}

Keyword: female-oriented male-male erotica, taboo love, sexual orientation, addiction, fNIRS 


\section{Introduction}

Female-oriented male-male erotica, as a subculture that refers to films and television, comics, anime, and novels about boys' love (Mizoguchi, 2003) and focuses on sexual scenarios rather than other aspects, such as characters (M. J. McLelland et al., 2015; Mizoguchi, 2003), is currently having growing influence on individuals.

As a kind of subculture, like a new sexual orientation, female-oriented male-male erotica fans are not recognized by mainstream culture fans as being a subculture that will persist. Recently, with the development of an open society and the development of the Internet, female-oriented male-male erotica began to enter the public view. Meanwhile, the base of female-oriented male-male erotica fans was also growing rapidly and becoming more popular around the world(M. McLelland \& Yoo, 2007), especially in China(Chou \& University, 2010), Japan(Flowers, 2016; Galbraith, 2015), and the USA(Annett, 2011, pp. 1906-2010). Moreover, the interest of female-oriented male-male erotica fans was fueled with an increasingly wider sexual orientation recognized in Anglophone countries(Madill \& Zhao, 2021). As of July 15, 2012, 110,593 people participated in the network survey of male-male erotica fans conducted by the famous Tencent website in China(Qiuxia \& Kaixin, 2013); among these people, only $15.96 \%$ and $2.75 \%$ chose "not knowing what male-male erotica fans" were or "no tendency at all of being a male-male erotica fan", respectively. The primary male-male erotica fans and the extreme male-male erotica fans accounted for $37.54 \%$ and $43.76 \%$ of respondents, respectively, and the age distribution was mainly concentrated in the range of 16 22 years, accounting for $50.45 \%$ of respondents. Consequently, male-male erotica fans have been widespread in society.

Considering the massive quantity of related paraphernalia available and the considerable amount of time, money and energy costs invested by female-oriented male-male erotica fans, understanding the reason individuals indulge in male-male erotica is of great relevance to parents and education institutions. Therefore, a thorough understanding of the underlying behavior and neurocognitive processes exhibited by male-male erotica fans is required. In China, male-male erotica is still taboo. Female- 
oriented male-male erotica fans were motivated to break discriminatory and gender constraints and enjoy incorporating traditional gender norms into homosexual love stories while reading or creating male-male erotica productions (Chou \& University, 2010). Around the world, such motivation has been described as having many dimensions(Pagliassotti, 2008, 2016); showing cross-cultural differences(Zsila et al., 2018), such as rejection or resisting conservative patriarchal or parental critics about sex and gender(Xu \& Yang, 2013; Zhang, 2016); as well as involving a few males(Nagaike, 2015), but mostly females(Madill \& Zhao, 2021).

Societal influences and various sexual orientations have multiple physiological causes, such as genetics and brain structure(Quinsey, 2006). Moreover, the structural and functional aspects of the brain, such as gray matter volume in the right caudate, functional activity in the left putamen, and functional connectivity of the right caudate to the left dorsolateral prefrontal cortex, can be influenced by pornography(Kühn \& Gallinat, 2014). Internet pornography addiction(Brand et al., 2016) and problematic pornography use(Gola et al., 2017) can influence the ventral striatum. Problematic pornography use was also regarded as an addiction(Gola et al., 2017; Grubbs et al., 2018).

Female-oriented male-male erotica fans were intrigued by male-male erotica comics, anime, and novels, which contains many pornographic descriptions; however, there was no neural or experimental research about these individuals, especially female male-male erotica fans. If the previous studies just depended on a questionnaire survey, they could not have explored the mechanism deeply and causally. Therefore, this study aims to use functional near-infrared spectroscopy (fNIRS) to first explore the neural and behavioral mechanisms of male-male erotica fans watching male-male erotica images. 


\section{Materials and Methods}

\section{Participant}

All participants are females in rating image task and fNIRS experiment.

Rating Image:151 undergraduate participants from Henan University took part in the research (female-oriented male-male erotica fans $=80$, nonfans $=71$ ), each of them didn't have mental disorders or neurological diseases experience. After finish the experiments each of them will be paid 30RMB. 5 fans and 1 nonfan been removed because they flirted rating image which means they rate image regularly or they rate repeated images inconsistent. Due to data lose, 4 fans were not included in the analysis. Finally, there were 139 efficient data (71 fans and 68 nonfans) were analyzed.

fNIRS Experiment:85 undergraduate students from Henan University, who was paid $30 \mathrm{RMB}$ and not took part in the rating image experiment, with no history of neurological or psychiatric disease, signed the informed consent and took part in this study (female-oriented male-male erotica fans $=49$, nonfans $=36$ ). 2 fans did not finish the whole experiment. Because of the bad fNIRS data quality (more than 80 trials needed to be deleted), 14 fans and 6 nonfans were rejected by fNIRS Analysis, but their behavior data can be used. Finally, there were 35 fans and 30 nonfans fNIRS data, 47 fans, and 36 nonfans behavioral data were analyzed.

\section{Questionnaire}

\section{Description Variables Survey}

We made 17 items to inquiry attitude and behavior toward male-male erotica, shown in Table 1 items.

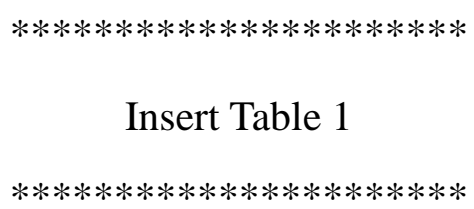

\section{Emotional Creativity Inventory (ECI) questionnaire}

The Emotional Creativity Inventory (ECI) questionnaire was first put forward in 1999(Averill, 1999) based on 489 subjects. It included 30 items, among three demission, namely, preparedness, referring to the understanding and learning capacity for one's 
own and other's emotions, novelty, referring to experiencing unusual emotions, and effectiveness/authenticity, referring to express emotions adroitly and honestly. Cronbach's alpha verified the reliability was 0.90 , showing good internal consistency.

It was revised to the China version in 2011(Jianyu, 2011) with 605 valid participants, which had the same demission but 26 items as 1 item had bad discrimination, three items had lower $(<0.4)$ factor loading. The final questionnaire structural model's Comparative Fit Index (CFI) was 0.984, the Root Mean Square Error of Approximation was 0.061 . The reliability was verified by Cronbach's $\alpha$, which was 0.828 .

\section{Attitudes Toward Lesbians and Gay Men (ATLG)}

Herek's Attitudes Toward Lesbians and Gay Men (ATLG), Cronbach's $\alpha$ was 0.90, included 20 items, firstly put forward in 1988 based on 280 subjects(Herek, 1988), revised in 1998, based on 322 subjects(Raja \& Joseph, 1998). It contained Attitudes Toward Lesbians (ATL) and Attitudes Toward Gay Men (ATG). The ATL can estimate the attitude toward lesbians. The ATG can estimate the attitude of gay men.

The Chinese version of Attitudes Toward Lesbians and Gay Men (CATLG) (Yong et al., 2020) was put forward in 2010 based on 937 subjects, including two subdemission. ATG, including 10 items, ATL including 10 items, CATLG's Cronbach's alpha was 0.898 .

\section{fNIRS Data acquisition}

The absorptivity of oxy- $\mathrm{Hb}$, deoxy- $\mathrm{Hb}$, and total- $\mathrm{Hb}$ was measured using a continuous-wave system (NIRX Scout $32 \times 32$, USA) and an $8 \times 7$ probe set covering the prefrontal cortex (PFC) with a total of 20 channels consisting of 8 light transmitters and 7 detectors. The fNIRS system in this study uses two different wavelengths $(785 \mathrm{~nm}$ and $830 \mathrm{~nm}$ ), and the frequency is adjusted according to wavelength and channel to avoid crosstalk. The distance of each probe is $30 \mathrm{~mm}$, and the sampling rate of the device is $7.8125 \mathrm{~Hz}$. The probe is mounted on the swimming cap according to the International 10-20 system and covers the prefrontal cortex. This study focused on the PFC region to explore brain function. Channel locations were shown in SI Appendix Fig 1. 


\section{Design}

\section{Rating Image}

Before fNIRS experiment, the images were rating. In the picture rating experiment, each participant needed to rate how arousing and pleasurable 353 gay or heterosexual images they saw on a 1-9 Likert scale. Arousal refers calmness or excitement, the closer rating to 9 , the more excited, pleasure refers to feeling pleasant or unpleasant, the closer rating to 9 , the more pleasure. To make sure the subject understood the task there were 20 repeated images in the experiment.

In picture-rating experiment. at the beginning of researchers talked word introduction with participants, then subjects need to signed the informed consent and finished a questionnaire which included two parts, in the first part the participant should answer a question "Are you a male-male erotica fans", in the second the part participants should fill out to the ECI and the CATLG). The picture-rating task began with word introduction, the participants will be informed during the following experiment, they should rate scale 1-9 each of the images how arousing and pleasurable by their right hand on numeric keypad according to the first feeling. After that, the picture-taking task which had 353 trials was began. Each of the trials, there was 2000 ms of the central fixation presented on the screen at first, then one of the images will be presented on the screen at random until the subject rate the two dimensions. After relaxing, the new trail began. The picture-rating task's process and example pictures were shown in SI Appendix Fig 2.

\section{Image Selected}

Depending on the arousal and pleasure results of the rating image experiment, firstly, the images, which the arousal $(t(118)=1.042, p=0.300)$ and pleasure $(t(118)$ $=0.265, p=0.791)$ had no significant difference between homosexual men images and heterosexual images, was evaluated within fans (arousal: $t(118)=0.043, p=0.965$, pleasure: $t(118)=0.407, p=0.685)$ and nonfans (arousal: $t(118)=1.302, p=0.196$, pleasure: $t(118)=0.100, p=0.921)$ to valid there was no difference between homosexual men images and heterosexual images in arousal and pleasure. Then, 60 
homosexual men and 60 heterosexual images were selected. Next, the mask images were created as reconstituted fragment (each fragment was 20 Pixels $\times 20$ Pixels) from homosexual men image as control images, the demo mask image was shown in Fig 1(A). Finally, the image's luminance was balanced by SHINE(Dal Ben, Rodrigo, 2021; Willenbockel et al., 2010) toolbox in MATLAB 2020a.

\section{fNIRS Experiment}

A questionnaire survey was asked to be finished after signing the informed consent. Then, the participants rested for 5 minutes after wearing an fNIRS hat to calm themselves. After that, experimenters introduce this experiment to participants to ensure they understood what they need to do. If there was no doubt, the experiment began. Each participant needed to finish 180 random trials, including 60 homosexual men, 60 heterosexuals, or 60 mask (nothing) images.

At first, in each trial, a fixation point was shown lasting 2 seconds; after that, the image was presented lasting 4 seconds, while the participants were asked to identify the image was homosexual men, heterosexual, or mask (nothing) image immediately when the image was shown. Then, they relaxed, lasting 8 seconds. The reaction time, accuracy, and fNIRS data were recorded during the experiments. The flew loop was shown in Fig 1(A).

$* * * * * * * * * * * * * * * * * * * * * *$

Insert Figure 1

$* * * * * * * * * * * * * * * * * * * * * *$ 


\section{Data Analysis}

\section{Behavior and Questionnaire Analysis}

The behavioral data was analyzed by SPSS 25 . In terms of behavioral data, there were two main effects: image classes, a within-variable with 3 level, homosexual men, heterosexual, and mask, and another was the group, a between-variable including malemale erotica fans and nonfans compared by mixed ANOVA. The accuracy (\%) and reaction time (ms) was analyzed, respectively. Post Hoc tests corrected by LeastSignificant Difference (LSD).

As for questionnaire data, analyzed by pingouin 0.3 .10 (Vallat, 2018) in Python 3.8.8, two groups were compared in description variables survey, ATG, ATL, and total ATLG score, 3 ECI sub-demission, total ECI score, using t-test.

\section{fNIRS Analysis}

\section{Preprocessing}

fNIRS data were analyzed by MNE 0.22(Gramfort et al., 2014) with Python 3.8.8. After acquiring raw data as light intensity data, it was transposed to optical density data. Then, scalp coupling index (sci) was used to evaluate the channel quality of the coupling between the optodes and the scalp(Pollonini et al., 2014). If the sci of the channel were less than 0.5 , the channel would be rejected and interpolated, next removing baseline shift and spike artifacts by temporal derivative distribution repair (TDDR)(Fishburn et al., 2019). After which, optical density data was converted to hemoglobin concentration data by beer lambert law, where the partial pathlength factor is 0.1 as $\mathrm{Oxy}-\mathrm{Hb}$, representing oxygen delivery to tissues, Deoxy- $\mathrm{Hb}$, representing oxygen extraction from the tissue, and Total- $\mathrm{Hb}$, representing total blood volume delivered (N. Tam et al., 2017; N. D. Tam \& Zouridakis, 2014).

A band-pass filter was set after that, and the high-frequency pass threshold was 0.01 to remove slow drifts. Since the low-frequency pass threshold was subjective (some studies used $0.1,0.2$, or more than 0.2 ) and there was no standard, this study set it per 0.01 from 0.1 to 0.5 to balance this disputation multi-analysis to avoid the unwanted heartbeat wave. Then, the hemoglobin concentration data was split by mark 
timepoint from -2 second to 12 second. Each fragment subtracted the mean of baseline ( -2 second to 0 second) and then averaged within each condition per timepoint.

\section{Estimate the Stability of Multi-analysis}

A precise (point to point) method was applied. To be specific, every timepoint in 3 different hemoglobin concentration data in each channel after baseline need to compare between male-male erotica fans and nonfans within homosexual men, heterosexual, and mask images by mixed ANOVA by pingouin 0.3.10 (Vallat, 2018). This study used the False Discovery Rate (FDR) correction firmly controlled the level alpha's family-wise error rate(Genovese et al., 2002) to deal with the Post Hoc Multiple Comparisons independently after filtering.

To move forward a single step to avoid false-positive results. A cluster threshold was set as 10, which means, if the number of the significant-difference successive timepoint was less than 10, these results probably were false-positive results, and this study regarded it as insignificant.

There were 41 comparing times totally at a timepoint because of the various lowfrequency pass threshold filters. So, to estimate the stability of multi-analysis, a stability index (SI) was defined as

$$
S I=\frac{S_{\text {Total }}}{S_{C[t]}}=\frac{\int_{t p_{\text {end }}}^{t p_{\text {start }}} C[t] d t}{N_{\text {compared }} \times\left(t p_{\text {end }}-t p_{\text {start }}\right)}
$$

where $C[t]$ was the discrete significant-difference distribution curve, $t p_{\text {start }}$ was the first timepoint which had a significant difference in the main effect. $t p_{\text {end }}$ was the last timepoint which had significant results, $N_{\text {compared }}$ was the total times of comparing in each timepoint. The schematic diagram was shown in Fig 1(B).

SI was available to symbolize the ratio of the significant results among all comparing. The range of SI was from closed interval 0 to closed interval 1 . The closer SI was to 0 , the more unreliable and instability the result was. As if only 1 significant result was found among a 100 timepoints range $\left(t p_{\text {end }}-t p_{\text {start }}\right)$, which compared 10 times respectively, SI was $0.001\left(S I=\frac{1}{10 \times 100}=0.001\right)$, mostly it was a false positive result, vice versa. 


\section{Statistical Analysis of averaged hemoglobin concentration data}

After comparing the averaged amplitude among channels, to explore the total effect among channels, the hemoglobin concentration data were averaged by 35 and 30 subjects, respectively for male-male erotica fans and nonfans groups, 41 low-frequency pass threshold, and 96 timepoints, thus using ANOVA to compare the main effects by SPSS 25. Post Hoc tests corrected by LSD, and after it, this study did a sample analysis to compare the averaged hemoglobin concentration data within each main effect level.

\section{Combining fNIRS with Questionnaire Analysis}

To validate the relationship of the total score of emotional creativity and the averaged brain activity, this study used a one-order linear regression model fitted by Ordinary Least Squares (OLS) based on statsmodels 0.12.2 (Montgomery \& Peck, 1992) package in Python 3.8.8. Within 3 categories of images, 3 categories of hemoglobin concentration data, and between 2 groups, the linear regression model using the averaged amplitude of the whole PFC as Y and the emotional creativity demission as X to estimate the model, using $\mathrm{R}^{2}$ estimated by Maximum Likelihood Estimation (MLE) to validate the linear model, which was

$$
\mathrm{Y}=\beta \mathrm{X}+\varepsilon
$$

where $\beta$ was regression coefficient and $\varepsilon$ was intercept. The model validity was verified by $F$ test. 


\section{Result}

\section{Behavior and Questionnaire Results}

As for reaction time, the significant differences can be found in the main effect image $\left(F(2,162)=493.759, p<0.000, \eta_{p}^{2}=0.884\right)$, and group $(F(2,162)=12.422, p$ $\left.<0.000, \eta_{\mathrm{p}}^{2}=0.133\right)$, but no significant difference between interactive effect $(F(1,81)$ $\left.=2.294, p=0.134, \eta_{p}^{2}=0.024\right)$, and the sample analysis results was described in Fig 1C. Post Hoc tests showed that the reaction time of homosexual men image (M (SD) $=$ $1075.336(227.869) \mathrm{ms})$ and the heterosexual image $(\mathrm{M}(\mathrm{SD})=1064.918(212.004) \mathrm{ms})$ were higher $(p<0.000$, respectively) than mask image $(\mathrm{M}(\mathrm{SD})=776.050(175.387)$ $\mathrm{ms})$.

In term of accuracy, the result, which was the image effect $(F(2,162)=53.481, p$ $\left.<0.000, \eta_{p}^{2}=0.398\right)$, the group effect $\left(F(1,81)=0.866, p=0.011, \eta_{p}^{2}=0.011\right)$, and interactive effect $\left(F(2,162)=3.470, p=0.033, \eta_{p}^{2}=0.041\right)$, was analyzed by mixedanalysis, and the sample analysis results was described in Fig 1D. Post Hoc tests showed that the accuracy of homosexual men image $(\mathrm{M}(\mathrm{SD})=0.955(0.001))$ was lower $(p=0.001)$ than heterosexual image $(\mathrm{M}(\mathrm{SD})=0.970(0.001))$, which was lower $(p<0.000)$ than mask image $(\mathrm{M}(\mathrm{SD})=0.994(0.000))$.

Questionnaire results did not find the significant difference between fans and nonfans within ECI score and the other questionnaire results were described in Table 1. The average age of first exposure to male-male erotica was 16.07( $\mathrm{SD}=2.26)$.

\section{fNIRS Results}

\section{Result of estimating SI score}

SI Appendix Fig 3 showed the data in 0.1, 0.3, and $0.5 \mathrm{~Hz}$ low-pass threshold frequency of channel $1 \mathrm{HbO}, 3 \mathrm{HbR}$, and $18 \mathrm{Hb}$-Total and these channels' effect size and SI score. As shown in Fig 2(C) with SI Appendix Fig 1, right PFC showed a wider response between groups and images. More precisely, after mixed-ANOVA and FDR correction with the $0.05 p$-threshold value, the $\mathrm{Oxy}-\mathrm{Hb}$ in channels $1,2,9,16,17,18$ and the Total-Hb in channels $1,2,9,15,16,17,18$ were significantly different between 
female male-male erotica fans and nonfans. Moreover, left PFC (channel 1) also showed the Oxy-Hb and Total- $\mathrm{Hb}(0.964,0.911$, respectively) with the most stable main effect in the two groups, shown in Fig 2(A) and Fig 2(B). Next was channel 18 (0.914, 0.883, respectively). Deoxy-Hb was not sensitive to this effect. Only channel 3, with 0.547 SI score, had significant difference. All the absolute value of nonfans' positive response was smaller than that of fans' negative one.

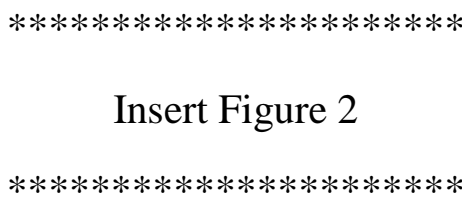

Insert Figure 2

$* * * * * * * * * * * * * * * * * * * * * *$

As for the image effect, the Oxy-Hb in channels 1, 15, 16, 17, 19, 20 and the Deoxy$\mathrm{Hb}$ in channels $3,5,7,12,16,17,19,20$ were significantly different among 3 categories of images. In Total-Hb, only channel 16 had a significant difference (homosexual men > Heterosexual > Mask, $\mathrm{SI}=0.863$ ). Oxy-Hb in channel 16 (homosexual men > Heterosexual $>$ Mask, $\mathrm{SI}=0.936$ ) and Deoxy-Hb in channel 19 (homosexual men > Mask, Heterosexual > Mask, $\mathrm{SI}=0.878$ ) had the most stable main effect; next was Oxy$\mathrm{Hb}$ in channel 19 (homosexual men > Mask, Heterosexual > Mask, SI =0.930). channels 16 and 19 results were shown in SI Appendix Fig 4. The effect size of channels 1, 16, 19 was shown in SI Appendix Fig 5.

Fig 3(A) showed the topo map of PFC, describing the blood oxygen distribution at 1st, 4th, 7th, and 10th seconds.

\section{$* * * * * * * * * * * * * * * * * * * * * * *$ \\ Insert Figure 3}

\section{Statistical Results of averaged hemoglobin concentration data}

ANOVA and Post Hoc results were showed in Table 2. Totally, Oxy-Hb, Deoxy$\mathrm{Hb}$, and Total-Hb all showed averaged response of fans was small than that of nonfans, i.e. negative response of fans was larger than that of nonfans. As well as images in a similar way, Oxy-Hb and Total-Hb showed that of both heterosexual and homosexual men was larger than that of mask, Deoxy-Hb showed that of heterosexual was larger than that of both mask and homosexual men, shown in Fig 1(E). 
$* * * * * * * * * * * * * * * * * * * * * *$

Insert Table 2

$* * * * * * * * * * * * * * * * * * * * * * *$

\section{Combining fNIRS with Questionnaire Results}

The regression coefficient $\beta$ within the relationship between the mask image and total score of ECI in Oxy-Hb and Total-Hb was significantly valid. All regression results were shown in Fig 3(B). 


\section{Discussion}

According to this study most females began to contact male-male erotica production at puberty (about 16 years old), and then those who viewed male-male erotica had a considerable difference in performance from those who had no history of male-male erotica exposure. Those who viewed male-male erotica spent more time and money than they expected on male-male erotica, with no interest in other things; treated male-male erotica as the necessary pleasure; and used it to relieve their negative mood. Their behavior is similar to addictive behavior(Barke et al., 2012; Carnes et al., 2012; Lai et al., 2013). Moreover, the psychological gender of their self-identity was changed. Also, their attitude toward homosexuality was more positive.

Furthermore, this study was the first to elucidate the neural mechanism affected when individuals viewed homosexual men images. The effect observed when females viewed male-male erotica images was robust; the averaged PFC responses in females were different after viewed heterosexual images, as was their behavioral performance. Between fans and nonfans, the effect of experiencing male-male erotica material can easily be identified. Specifically, nonfans shared a positive response, but fans who had long-term contact had the opposite response when viewing homosexual men images. For viewing heterosexual images, both fans and nonfans had a negative response, but that of fans was more intense.

Emotion and PFC have the high connection(Dixon et al., 2017), both positive and negative emotions(Seo et al., 2014). Long-term contact with male-male erotica improved the negative response in the left (channels 1, 2, and 3), middle (channel 9), and right (channels 15, 16, 17, and 18) PFC; also, viewing homosexual men images activated in the left (channels 1, 3, 4, and 7), middle (channel 12), and right (channels 15, 16, 17, 19, and 20) PFC, totally, showing wider responses in right PFC. Fans during viewing homosexual men images might activity an intense emotion than nonfans, and it may be caused by reward-seeking motivation, even addiction.

Wider response in right PFC, sometimes it referred to motivational drives including reward-seeking and relief from negative emotions contributes to compulsive addictive 
behaviors(Wu et al., 2020), or approach-avoidance conflict (AAC) refers to situations associated with both rewarding and threatening outcomes(Chrysikou et al., 2017). Consequently, when fans viewed homosexual men images, they might identify these images as reward, like the pornography addiction(Gola et al., 2017; Kühn \& Gallinat, 2014). Our questionnaire results showed that they more addicted in the male-male erotica productions than nonfans. So, male-male erotica for them was one of the potential addicted reward can influence their brain, the motivation of contacting malemale erotica drives them seeking, thus spending more money and time.

However, the masked image results were not consistent with the original hypothesis. Even though the oxygenated hemoglobin $(\mathrm{Oxy}-\mathrm{Hb})$ and deoxygenated hemoglobin (Deoxy-Hb) PFC responses to masked images were different from that of heterosexual images, viewing masked images also caused a negative response and revealed a distinction between groups. As the regression results combining fNIRS with Emotional Creativity Inventory (ECI) results showed, only mask images had a significant regression effect on the PFC response. It seems that fans had an autonomous capacity to naturally complete a jigsaw puzzle based on their emotional creativity. However, no experimental study has proven this conjecture.

The primary limitation of this study is that only females took part in this study; as no males were included, we cannot be sure how males would perform. The conclusions discussed cannot be transferred from females to males; thus, the results do not directly apply to everyone. The masked image used in this study seemed not an ideal control condition because of the unexpected negative response. However, depending on the ECI questionnaire, the results can be explained in part. In the following research, we are considering adding other sexual related stimuli, like homosexual women pictures, or naked body, and setting more sexual unrelated neutral control group, like scenery, buildings, and animals. As a first-exploration experiment, this study provides some results as expected and a hypothesis that needs to be verified in future studies.

In conclusion, our study focuses on a special female colony, which oriented malemale erotica. And we found that among them most girls indulge in male-male erotica productions at puberty, and these fans showed a trend indicating addiction. The 
experience of long-term or no contact with male-male erotica could influence the brain response in the PFC and one's behavior performance. The PFC neural response embodied a new but taboo sexual attraction for girls, with potential addiction tendency. 


\section{Reference}

Annett, S. (2011). Animating transcultural communities: Animation fandom in North America and East Asia from 1906-2010. http://search.proquest.com/docview/1223528737?accountid=14553

Averill, J. R. (1999). Individual Differences in Emotional Creativity: Structure and Correlates. Journal of Personality, 67(2), 331-371. https://doi.org/10.1111/1467-6494.00058

Barke, A., Nyenhuis, N., \& Kröner-Herwig, B. (2012). The German Version of the Internet Addiction Test: A Validation Study. Cyberpsychology, Behavior, and Social Networking, 15(10), 534-542. https://doi.org/10.1089/cyber.2011.0616

Brand, M., Snagowski, J., Laier, C., \& Maderwald, S. (2016). Ventral striatum activity when watching preferred pornographic pictures is correlated with symptoms of Internet pornography addiction. NeuroImage, 129, 224-232. https://doi.org/10.1016/j.neuroimage.2016.01.033

Carnes, P. J., Green, B. A., Merlo, L. J., Polles, A., Carnes, S., \& Gold, M. S. (2012). PATHOS: A Brief Screening Application for Assessing Sexual Addiction. Journal of Addiction $\quad$ Medicine, $\quad 6(1), \quad 29-34$. https://doi.org/10.1097/ADM.0b013e3182251a28

Chou, D., \& University, T. C. (2010). Exploring the Meaning of Yaoi in Taiwan for Female Readers: From the Perspective of Gender. 19(1).

Chrysikou, E. G., Gorey, C., \& Aupperle, R. L. (2017). Anodal transcranial direct current stimulation over right dorsolateral prefrontal cortex alters decision 
making during approach-avoidance conflict. Social Cognitive and Affective Neuroscience, 12(3), 468-475. https://doi.org/10.1093/scan/nsw140

Dal Ben, Rodrigo. (2021). Luminance control of colored images. https://doi.org/10.17605/OSF.IO/AUZJY

Dixon, M. L., Thiruchselvam, R., Todd, R., \& Christoff, K. (2017). Emotion and the prefrontal cortex: An integrative review. Psychological Bulletin, 143(10), 1033-1081. https://doi.org/10.1037/bul0000096

Fishburn, F. A., Ludlum, R. S., Vaidya, C. J., \& Medvedev, A. V. (2019). Temporal Derivative Distribution Repair (TDDR): A motion correction method for fNIRS. NeuroImage, 184, 171-179. https://doi.org/10.1016/j.neuroimage.2018.09.025

Flowers, T. A. (2016). A Review of Boys Love Manga and Beyond. History, Culture, and Community in Japan. The Comics Grid: Journal of Comics Scholarship, 6(1), 15. https://doi.org/10.16995/cg.77

Galbraith, P. W. (2015). Moe talk: Affective communication among female fans of Yaoi in Japan.

Genovese, C. R., Lazar, N. A., \& Nichols, T. (2002). Thresholding of Statistical Maps in Functional Neuroimaging Using the False Discovery Rate. NeuroImage, 15(4), 870-878. https://doi.org/10.1006/nimg.2001.1037

Gola, M., Wordecha, M., Sescousse, G., Lew-Starowicz, M., Kossowski, B., Wypych, M., Makeig, S., Potenza, M. N., \& Marchewka, A. (2017). Can Pornography be Addictive? An fMRI Study of Men Seeking Treatment for Problematic Pornography Use. Neuropsychopharmacology, 42(10), 2021-2031. 
https://doi.org/10.1038/npp.2017.78

Gramfort, A., Luessi, M., Larson, E., Engemann, D. A., Strohmeier, D., Brodbeck, C., Parkkonen, L., \& Hämäläinen, M. S. (2014). MNE software for processing MEG and EEG data. NeuroImage, 86, 446-460. https://doi.org/10.1016/j.neuroimage.2013.10.027

Grubbs, J. B., Wilt, J. A., Exline, J. J., Pargament, K. I., \& Kraus, S. W. (2018). Moral disapproval and perceived addiction to internet pornography: A longitudinal examination: Moral Disapproval and Perceived Addiction. Addiction, 113(3), 496-506. https://doi.org/10.1111/add.14007

Herek, G. M. (1988). Heterosexuals' attitudes toward lesbians and gay men: Correlates and gender differences. Journal of Sex Research, 25(4), 451-477. https://doi.org/10.1080/00224498809551476

Jianyu, S. (2011). The revision of emotional creativity iventory for college students and the relation between emotional creativity and big five personality. University of Jinan.

Kühn, S., \& Gallinat, J. (2014). Brain Structure and Functional Connectivity Associated With Pornography Consumption: The Brain on Porn. JAMA Psychiatry, 71(7), 827. https://doi.org/10.1001/jamapsychiatry.2014.93

Lai, C.-M., Mak, K.-K., Watanabe, H., Ang, R. P., Pang, J. S., \& Ho, R. C. M. (2013). Psychometric Properties of the Internet Addiction Test in Chinese Adolescents. Journal of Pediatric Psychology, 38(7), 794-807. https://doi.org/10.1093/jpepsy/jst022 
Madill, A., \& Zhao, Y. (2021). Female-Oriented Male-Male Erotica: Comparison of the Engaged Anglophone Demographic and That of the Greater China Area. Sexuality \& Culture, 25(2), 562-583. https://doi.org/10.1007/s12119-02009783-9

McLelland, M. J., Nagaike, K., Suganuma, K., \& Welker, J. (Eds.). (2015). Boys love manga and beyond: History, culture, and community in Japan. University Press of Mississippi.

McLelland, M., \& Yoo, S. (2007). The International yaoi boys' love fandom and the regulation of virtual child pornography: The implications of current legislation. Sexuality Research and Social Policy, 4(1), 93-104. https://doi.org/10.1525/srsp.2007.4.1.93

Mizoguchi, A. (2003). Male-Male Romance by and for Women in Japan: A History and the Subgenres of" Yaoi" Fictions. US-Japan Women's Journal, 25, 49-75.

Montgomery, D. C., \& Peck, E. A. (1992). “Introduction to Linear Regression Analysis.” 2nd (Wiley).

Nagaike, K. (2015). Do heterosexual men dream of homosexual men?: BL Fudanshi and discourse on male feminization. In: McClelland M, Nagaike K, Suganuma K, Welker J, Editors. Boys Love Manga and Beyond: History, Culture, and Community in Japan Jackson: University Press of Mississippi, 189-209.

Pagliassotti, D. (2008). Reading boys' love in the West. Participations, 5 (2 (2008a)). https://www.participations.org/Volume\%205/Issue\%202/5_02_pagliassotti.ht $\mathrm{m}$ 
Pagliassotti, D. (2016). Qualitative Data from Research Reported in Dru Pagliassotti, Reading Boys' Love in the West. Participations.

Pollonini, L., Olds, C., Abaya, H., Bortfeld, H., Beauchamp, M. S., \& Oghalai, J. S. (2014). Auditory cortex activation to natural speech and simulated cochlear implant speech measured with functional near-infrared spectroscopy. Hearing Research, 309, 84-93. https://doi.org/10.1016/j.heares.2013.11.007

Qiuxia, H., \& Kaixin, X. (2013). Study on the gender role and self-concordant state of “yaoi fans.” Journal of Shaoguan University·Social Science, 34(1), 153-158. https://doi.org/1007-5348 (2013) 01-0153-06

Quinsey, V. L. (2006). The Etiology of Anomalous Sexual Preferences in Men. Annals of the New York Academy of Sciences, 989(1), 105-117. https://doi.org/10.1111/j.1749-6632.2003.tb07297.x

Raja, S., \& Joseph, S. (1998). Assessing Attitudes Toward Lesbians and Gay Men: The Modern Homophobia Scale. International Journal of Sexuality and Gender Studies, 3(2), 113-134. https://doi.org/10.1023/A:1023244427281

Seo, D., Olman, C. A., Haut, K. M., Sinha, R., MacDonald, A. W., \& Patrick, C. J. (2014). Neural correlates of preparatory and regulatory control over positive and negative emotion. Social Cognitive and Affective Neuroscience, 9(4), 494504. https://doi.org/10.1093/scan/nst115

Vallat, R. (2018). Pingouin: Statistics in Python. Journal of Open Source Software, 3(31), 1026. https://doi.org/10.21105/joss.01026

Willenbockel, V., Sadr, J., Fiset, D., Horne, G. O., Gosselin, F., \& Tanaka, J. W. (2010). 
Controlling low-level image properties: The SHINE toolbox. Behavior Research Methods, 42(3), 671-684. https://doi.org/10.3758/BRM.42.3.671

Wu, L., Potenza, M. N., Zhou, N., Kober, H., Shi, X., Yip, S. W., Xu, J., Zhu, L., Wang, R., Liu, G., \& Zhang, J.-T. (2020). A role for the right dorsolateral prefrontal cortex in enhancing regulation of both craving and negative emotions in internet gaming disorder: A randomized trial. European Neuropsychopharmacology, 36, 29-37. https://doi.org/10.1016/j.euroneuro.2020.04.003

Xu, Y., \& Yang, L. (2013). Forbidden love: Incest, generational conflict, and the erotics of power in Chinese BL fiction. Journal of Graphic Novels \& Comics, 4(1), 3043. https://doi.org/10.1080/21504857.2013.771378

Yong, Y., Shuiyuan, X., \& Ying, X. (2020). Theory Construction of the Attitudes Toward Gay Men and Lesbians in Chinese Context and Assessments in College Students. Chinese Journal of Clinical Psychology, 18(2), 174-176.

Zhang, C. (2016). Loving Boys Twice as Much: Chinese Women's Paradoxical Fandom of “Boys' Love” Fiction. Women's Studies in Communication, 39(3), 249-267. https://doi.org/10.1080/07491409.2016.1190806

Zsila, Á., Pagliassotti, D., Urbán, R., Orosz, G., Király, O., \& Demetrovics, Z. (2018). Loving the love of boys: Motives for consuming yaoi media. PLOS ONE, 13(6), e0198895. https://doi.org/10.1371/journal.pone.0198895 

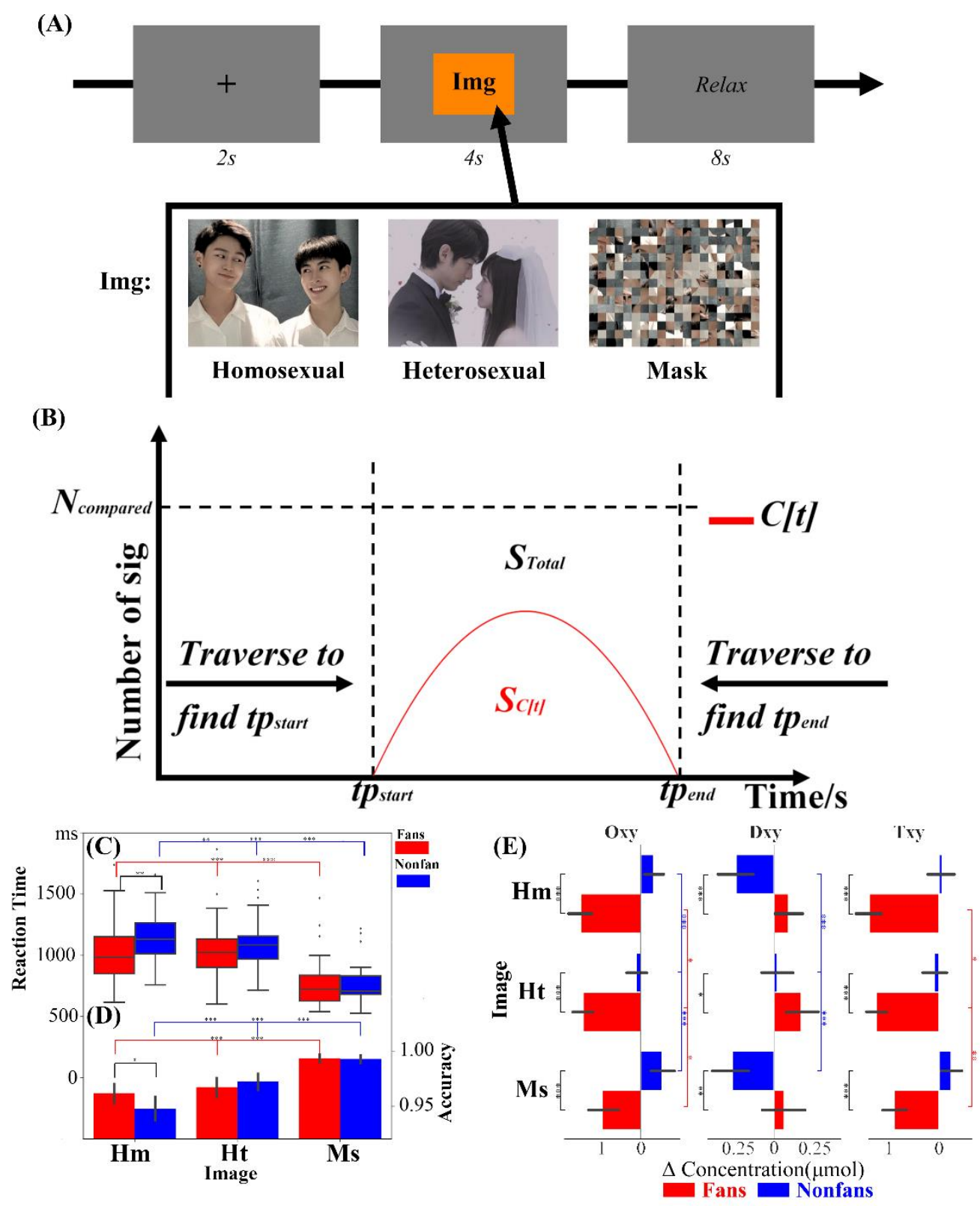

Fig. 1. (A) The flew loop schematic diagram of the trials. And It showed the demo of homosexual men images, heterosexual images, and mask images. Homosexual referred as to the homosexual men specially. (B) The schematic diagram of estimating the stability index (SI) of multi-analysis. (C) The reaction time was presented with the left axis. (D) The accuracy was presented with the right axis. (E) The bold activity of hemoglobin concentration data was shown. It represented the activity among channels. the abbreviation of Oxy-Hb, Dxy-Hb, and Total-Hb was Oxy, Dxy, and Txy, respectively. $*^{* *} p<0.001$; ${ }^{*} p<0.01 ;{ }^{*} p<0.05$. Hm: Homosexual men, Ht: 
Heterosexual, Ms: Mask. 


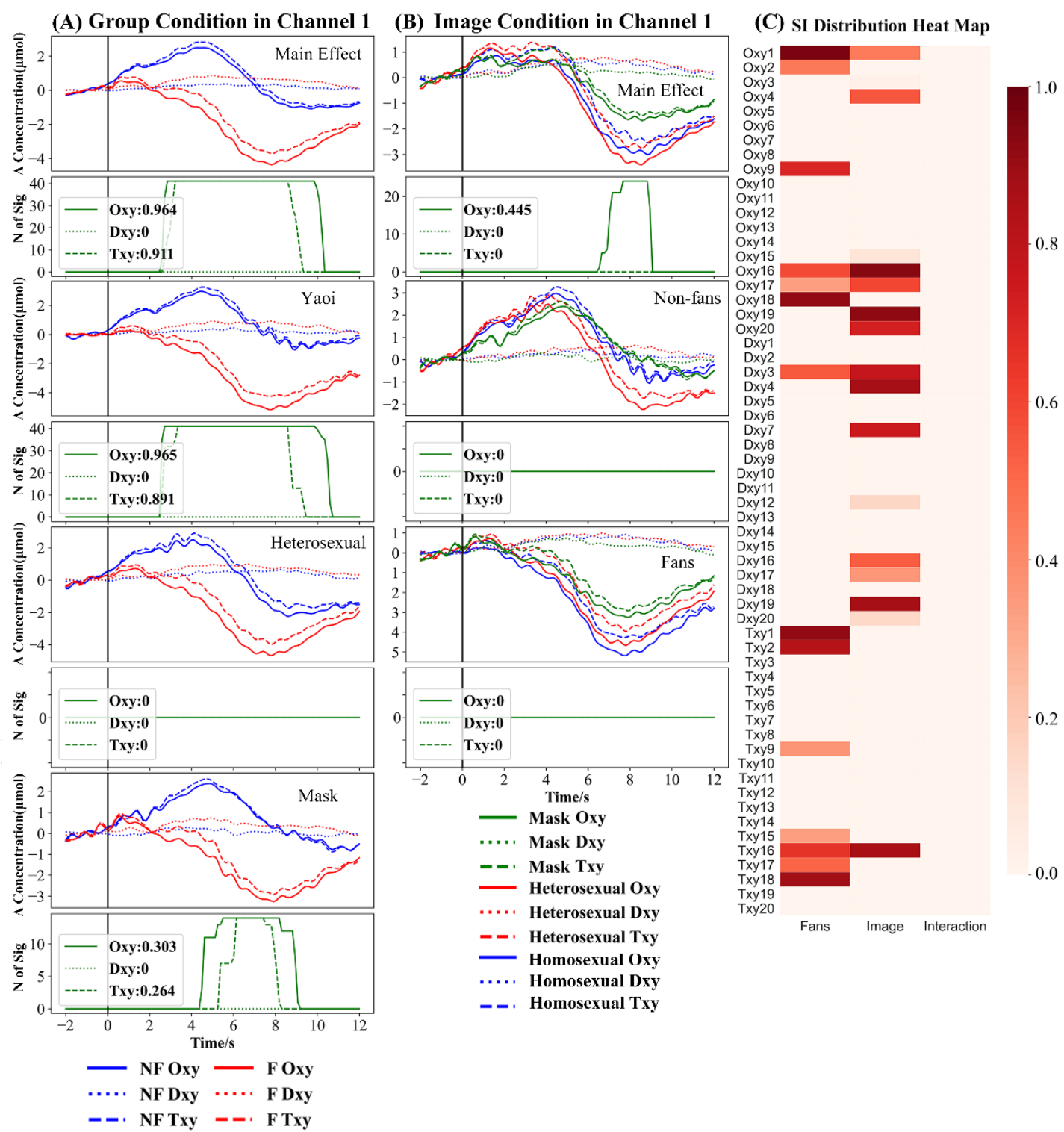

Fig. 2. (A) The hemoglobin concentration data of main effect of groups and the sample analysis among 3 categories of images in channel 1 to show the difference between male-male erotica fans and nonfans. The abbreviation of NF and $\mathrm{F}$ was nonfans and fans, respectively. (B) The hemoglobin concentration data of main effect of images and the sample analysis between male-male erotica fans and nonfans to show the difference among 3 categories of images. In A and $\mathrm{B}$, the green line presented the distribution of significant results and the legend show the SI score. Homosexual referred as to the homosexual men specially. (C) It showed the distribution of SI scores of two main effects and interactive effect in $\mathrm{Oxy}-\mathrm{Hb}, \mathrm{Dxy}-\mathrm{Hb}$, and Total-Hb of all 20 channels. In (A), (B), and (C), the abbreviation of Oxy-Hb, Dxy-Hb, and Total-Hb was Oxy, Dxy, and Txy, respectively. 

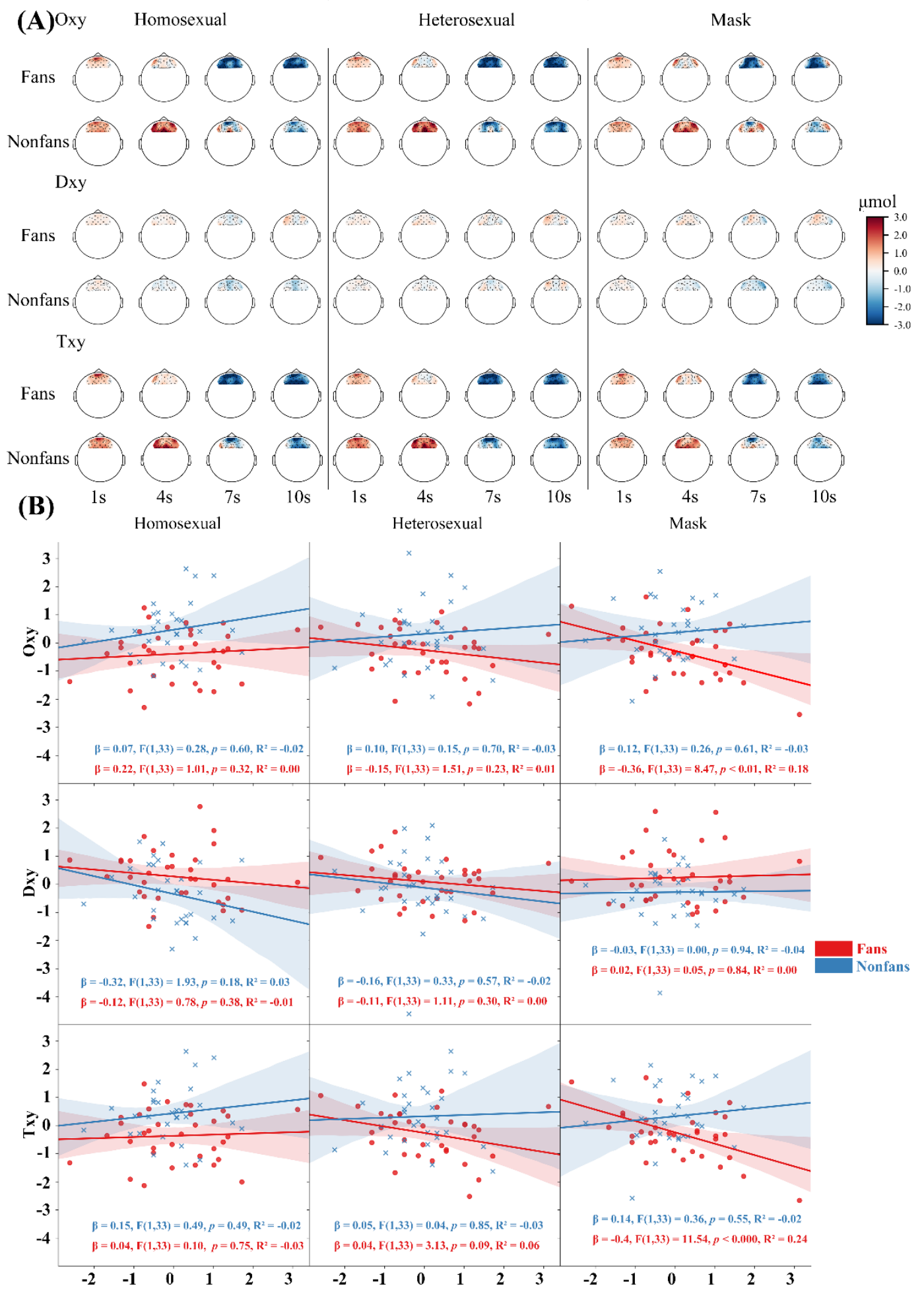

Fig. 3. (A) It showed the topo maps changing with time. The abbreviation of Oxy-Hb, Dxy-Hb, and Total-Hb was Oxy, Dxy, and Txy, respectively. (B) It showed the regression results, the $\mathrm{z}$ score of total PFC activity as $\mathrm{Y}$ and the $\mathrm{z}$ score of total ECI score as X. the abbreviation of Oxy-Hb, Dxy-Hb, and Total-Hb was Oxy, Dxy, and Txy, respectively. Homosexual referred as to the homosexual men specially. 


\begin{tabular}{|c|c|c|c|c|c|c|c|c|}
\hline \multirow{2}{*}{ Category } & \multirow{2}{*}{ Items } & \multirow{2}{*}{$\begin{array}{l}\text { Fans } \\
\mathrm{M}(\mathrm{SD})\end{array}$} & \multirow{2}{*}{$\begin{array}{l}\text { Nonfans } \\
\text { M(SD) }\end{array}$} & \multirow{2}{*}{$t(81)$} & \multirow{2}{*}{$p$} & \multicolumn{2}{|c|}{$95 \% \mathrm{CI}$} & \multirow{2}{*}{$\eta_{\mathrm{p}}^{2}$} \\
\hline & & & & & & lower & upper & \\
\hline \multirow{19}{*}{$\begin{array}{c}\text { Description } \\
\text { Variables } \\
\text { Survey }\end{array}$} & Your psychological gender is & $5.605(1.137)$ & $6.103(0.788)$ & 2.322 & 0.023 & 0.07 & 0.93 & 0.060 \\
\hline & I am a male-male erotica lover & $4.233(0.841)$ & $1.775(1.121)$ & -11.238 & 0.000 & -2.89 & -2.02 & 0.609 \\
\hline & $\begin{array}{l}\text { I always spent more time on the male-male erotica } \\
\text { than I expected }\end{array}$ & $3.209(1.036)$ & $1.325(0.797)$ & -9.322 & 0.000 & -2.29 & -1.48 & 0.507 \\
\hline & Now I'm not interested in TV series, anime, novels & & & & & & & \\
\hline & and so on that describe love between men and & $2.558(1.24)$ & $2.375(1.295)$ & -0.657 & 0.513 & -0.74 & 0.37 & 0.005 \\
\hline & women & & & & & & & \\
\hline & $\begin{array}{l}\text { When I am unhappy, male-male erotica can make } \\
\text { me happy }\end{array}$ & $3.721(0.934)$ & $1.75(1.08)$ & -8.862 & 0.000 & -2.41 & -1.53 & 0.489 \\
\hline & I put in a lot of time on the male-male erotica & $3.07(1.183)$ & $1.325(0.764)$ & -8.035 & 0.000 & -2.18 & -1.31 & 0.430 \\
\hline & $\begin{array}{c}\text { When I feel lonely, the male-male erotica can } \\
\text { relieve my loneliness }\end{array}$ & $3.349(0.997)$ & $1.5(1.038)$ & -8.264 & 0.000 & -2.29 & -1.4 & 0.452 \\
\hline & $\begin{array}{l}\text { When I'm upset, male-male erotica makes me feel } \\
\qquad \text { better }\end{array}$ & $3.651(0.897)$ & $1.625(1.148)$ & -8.917 & 0.000 & -2.48 & -1.57 & 0.494 \\
\hline & $\begin{array}{l}\text { Sometimes I am immersed myself in the world of } \\
\text { the male-male erotica }\end{array}$ & $3.326(1.017)$ & $1.575(1.174)$ & -7.236 & 0.000 & -2.23 & -1.27 & 0.390 \\
\hline & I'm willing to pump money into male-male erotica & $3.209(1.264)$ & $1.275(0.716)$ & -8.653 & 0.000 & -2.38 & -1.49 & 0.465 \\
\hline & $\begin{array}{l}\text { When I am anxious, male-male erotica can ease my } \\
\text { anxiety }\end{array}$ & $3.302(0.914)$ & $1.65(1.21)$ & -6.981 & 0.000 & -2.12 & -1.18 & 0.375 \\
\hline & $\begin{array}{l}\text { The idea of male-male erotica always comes to my } \\
\text { mind }\end{array}$ & $3.442(1.031)$ & $1.475(0.987)$ & -8.882 & 0.000 & -2.41 & -1.53 & 0.487 \\
\hline & $\begin{array}{l}\text { When I see two boys intimate contact in real life, I } \\
\text { am very excited }\end{array}$ & $3.93(1.033)$ & $2.225(1.209)$ & -6.886 & 0.000 & -2.2 & -1.21 & 0.367 \\
\hline & Male-male erotica makes my life more enjoyable & $4.116(1.775)$ & $1.875(1.137)$ & -10.347 & 0.000 & -2.67 & -1.81 & 0.570 \\
\hline & I find it difficult to communicate with the opposite & $2.605(1.178)$ & $2.5(1.24)$ & -0.393 & 0.695 & -0.63 & 0.42 & 0.002 \\
\hline & If I had a choice, I would change my gender & $2.442(1.368)$ & $1.725(0.933)$ & -2.805 & 0.006 & -1.23 & -0.21 & 0.085 \\
\hline & Total Attitudes & $90.744(6.779)$ & $72.725(12.006)$ & -8.336 & 0.000 & -22.34 & -13.7 & 0.465 \\
\hline \multirow[t]{4}{*}{ ATLG } & Attitudes Toward Gay Men (ATG) & $45.302(4.05)$ & $37.2(5.88)$ & -7.259 & 0.000 & -10.33 & -5.88 & 0.395 \\
\hline & Attitudes Toward Lesbians (ATL) & $45.442(3.283)$ & $35.525(7.002)$ & -8.162 & 0.000 & -12.35 & -7.48 & 0.457 \\
\hline & Total ECI score & $93.14(10.38)$ & $91.15(7.454)$ & -1.008 & 0.317 & -5.92 & 1.94 & 0.012 \\
\hline & Preparedness & $28.907(2.58)$ & $28.925(2.859)$ & 0.030 & 0.976 & -1.17 & 1.21 & 0.000 \\
\hline \multirow{2}{*}{$\mathrm{ECl}$} & Novelty & 46.93(7.564) & $45.275(6.114)$ & -1.100 & 0.275 & -4.65 & 1.34 & 0.014 \\
\hline & Effectiveness/Authenticity & $17.302(2.651)$ & $16.95(3.351)$ & -0.529 & 0.599 & -1.68 & 0.98 & 0.003 \\
\hline
\end{tabular}


Table 2

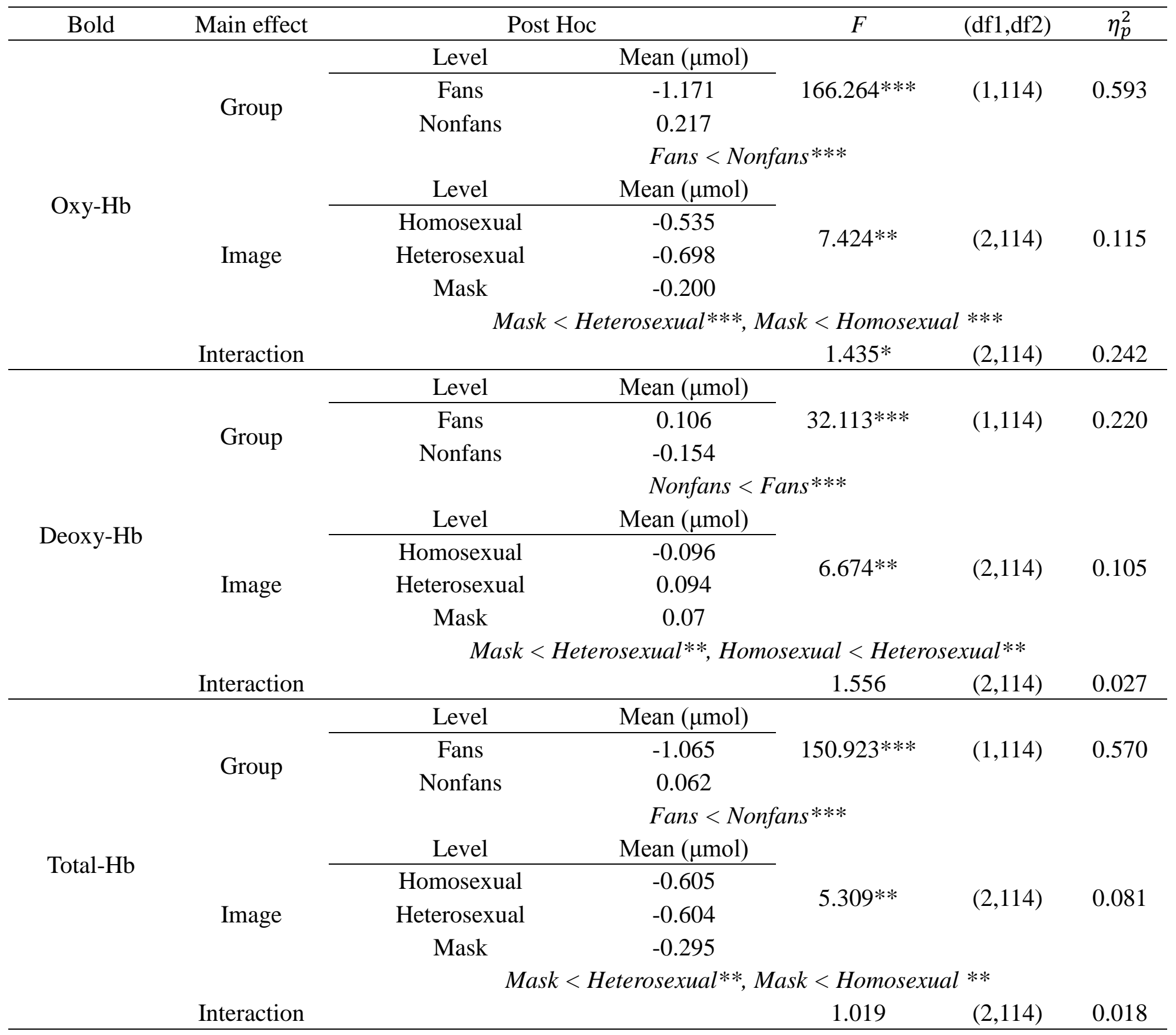

Note: $* * * p<0.001 ; * * p<0.01 ; * p<0.05$. In this table, Homosexual referred to as the homosexual men specially. 
(A)
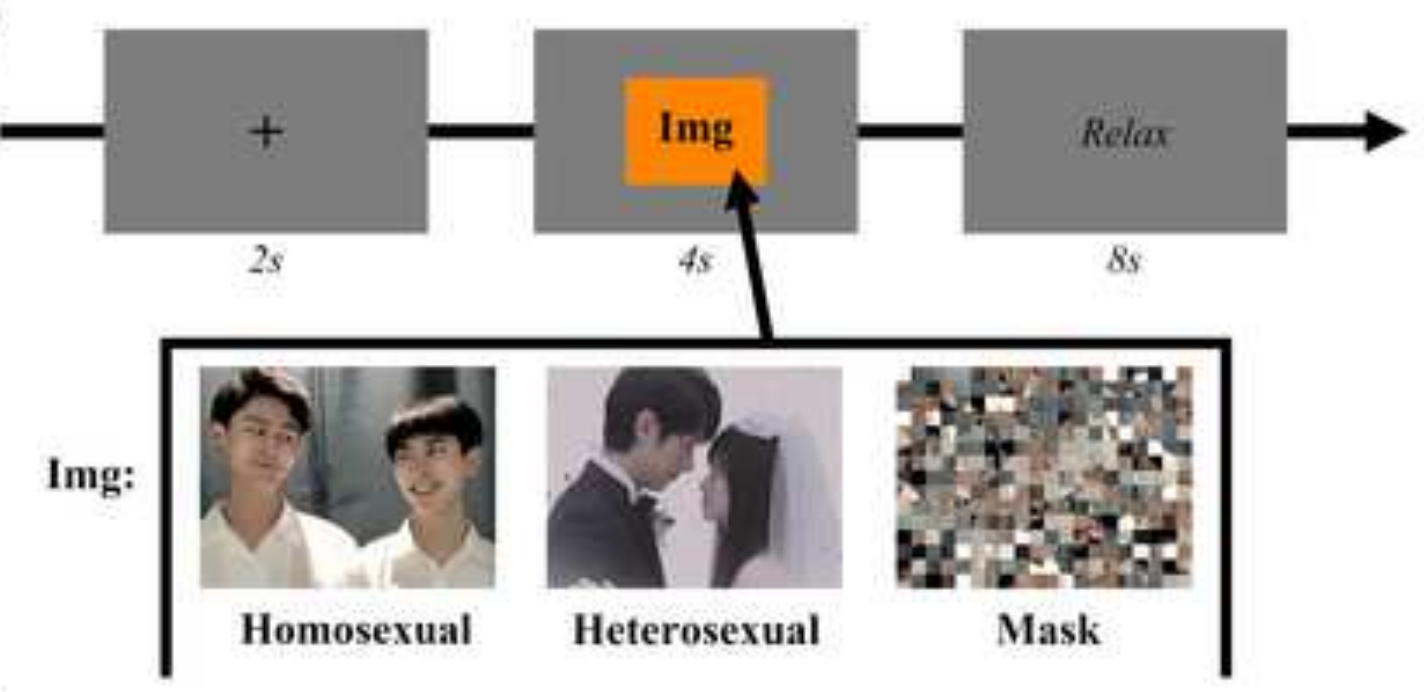

(B)
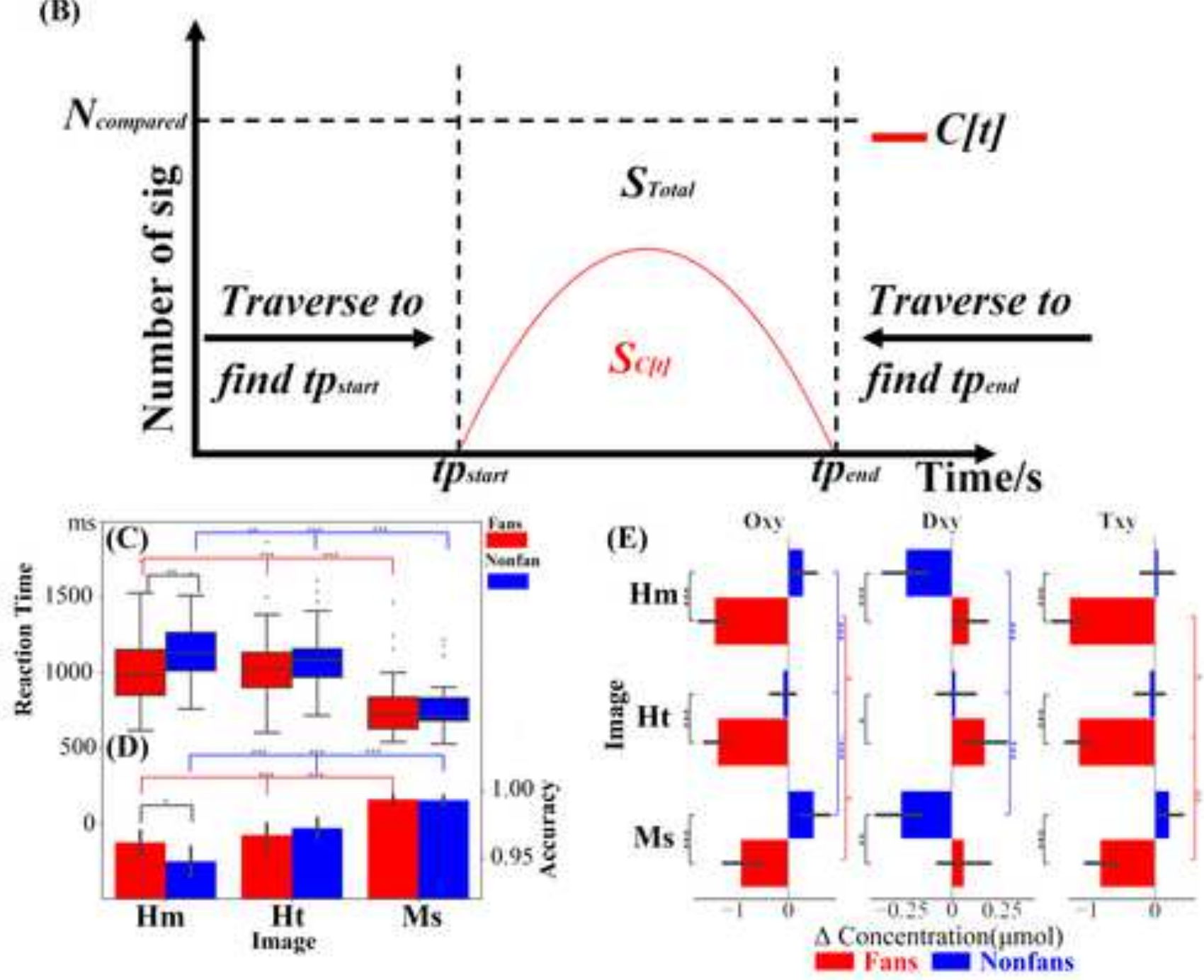
(A) Group Condition in Channel 1
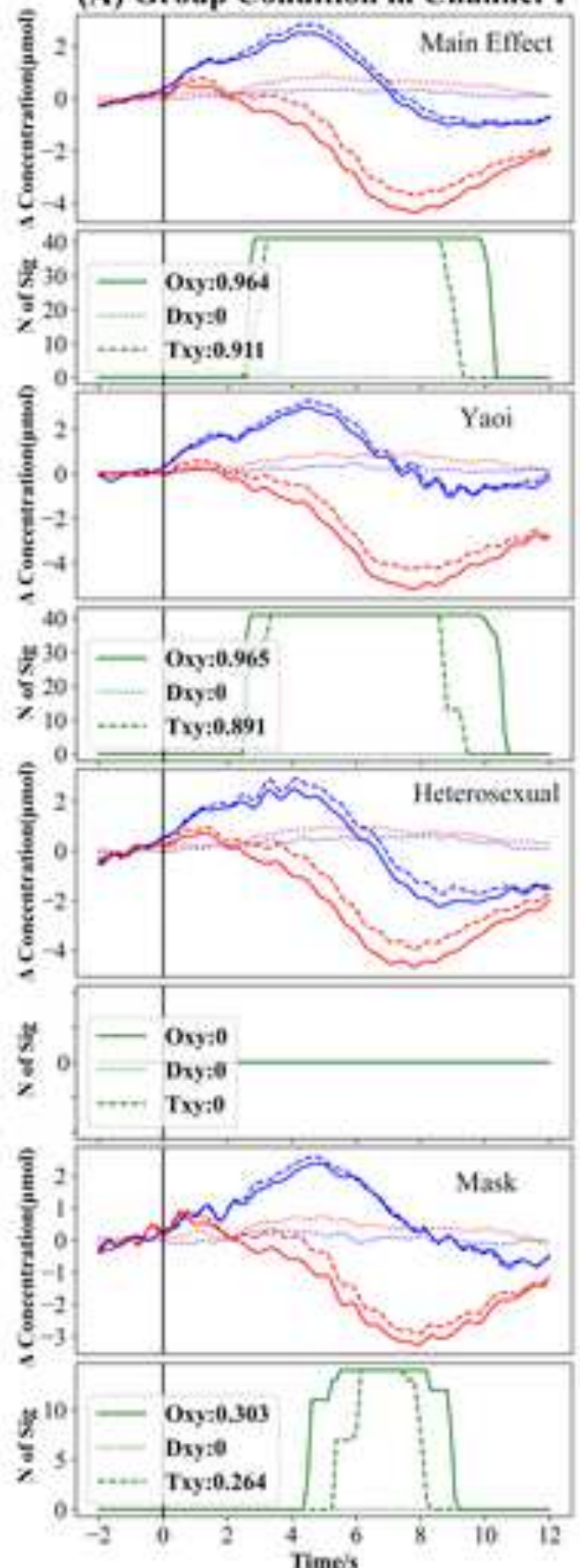

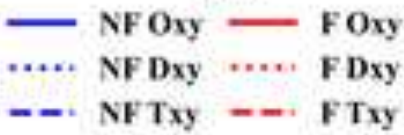

(B) Image Condition in Channel I
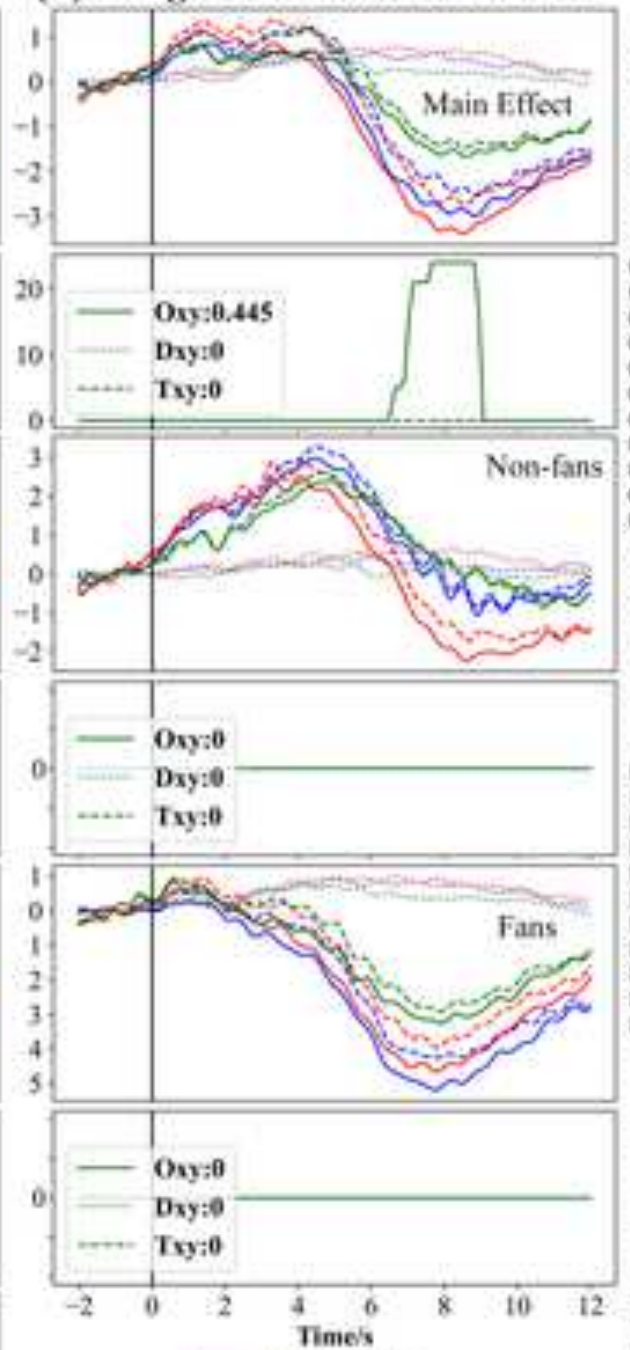

- Mask Oxy

+.,.) Mask Dxy

- Mask Tiy

- Heterosexeal Oxy

..... Heterosexual Dxy

--. Heterosexual Txy

- Hemesexual Oxy

..... Homosexual Dxy

-.. Homosexual Txy
(C) St Distribution Heat Map

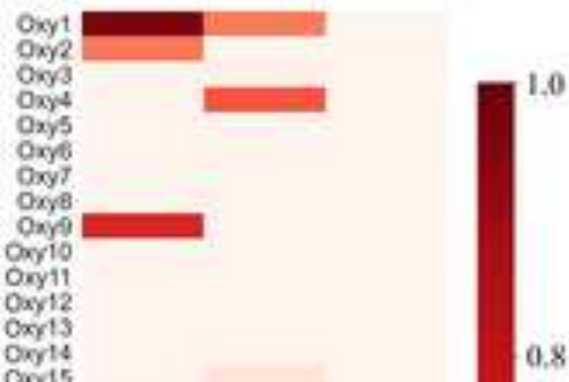

oxis

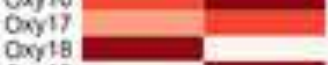

$0 \times 10$

$0 \times 20$

Dixy

Dxy3 D

Dxy 4

Dives

Dxy

Dxy?

Disy

Dxyto

Dxyi1
Oxy12

oxy/3

$0 x y 14$

$0 x 15$

Dxyl1

Oxy18

bxyl9

Dxyz20

Txy?

Txys

Twy4

Try5

Try?

Txys

trovio

Txy

Txy:

Txyl4

Txyil

Txyy?

Txyls

Txyl9

$7 \times y 20$

Fans hage interaction

\section{8}

6


(A) Oxy Homosexual

Heterosexual

Mask

Fans 40

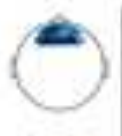

()

()

(a)

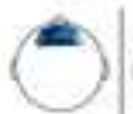

$\Leftrightarrow(\infty)$

(n)

Nonfans (4)

$(4)$

(i)

(2)

(a)

(6)

(n)

(a)

(a)

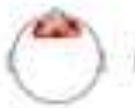

(a) (3)

Dxy

Fans

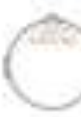

(3)
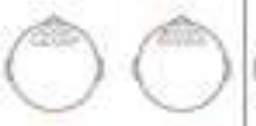

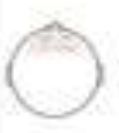

(a) $\mathrm{O}$

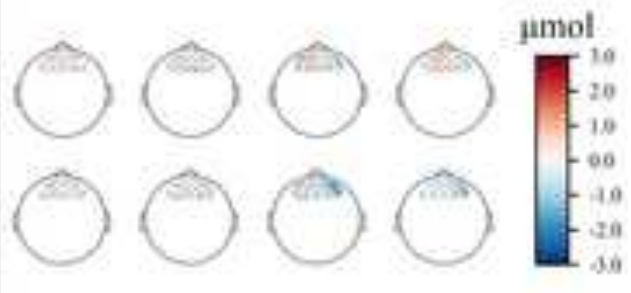

Nonfans

(i)

(

(a)

(b)

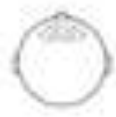

$\Leftrightarrow$

(a)
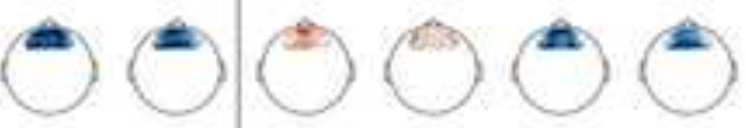

Nonfans

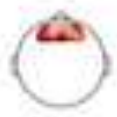

(a)

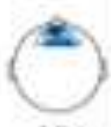

(B)

$4 s$

78

$10 \mathrm{~s}$

Homosexual
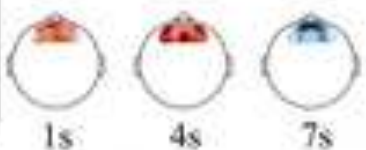

(4)

Heterosexual
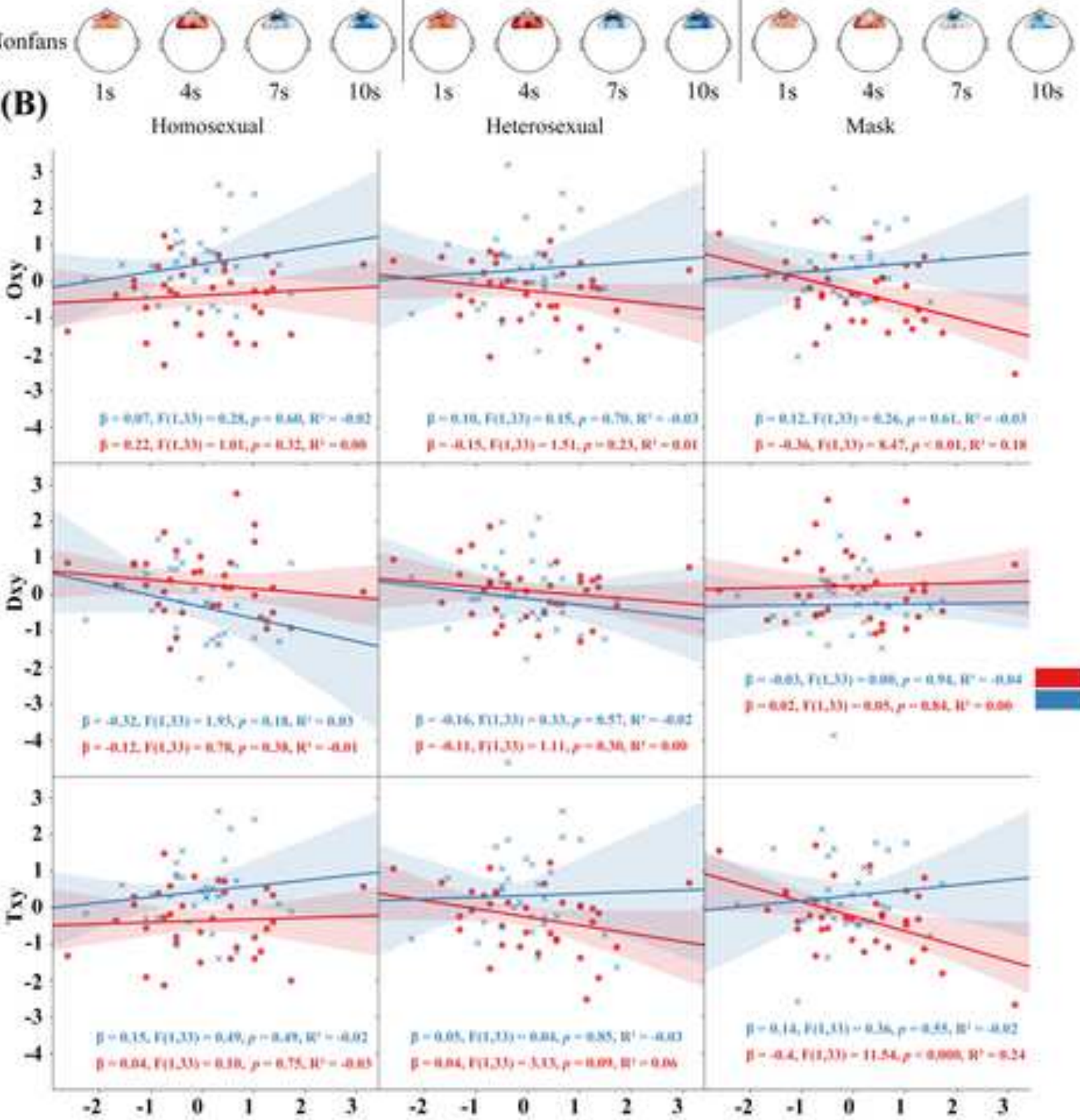


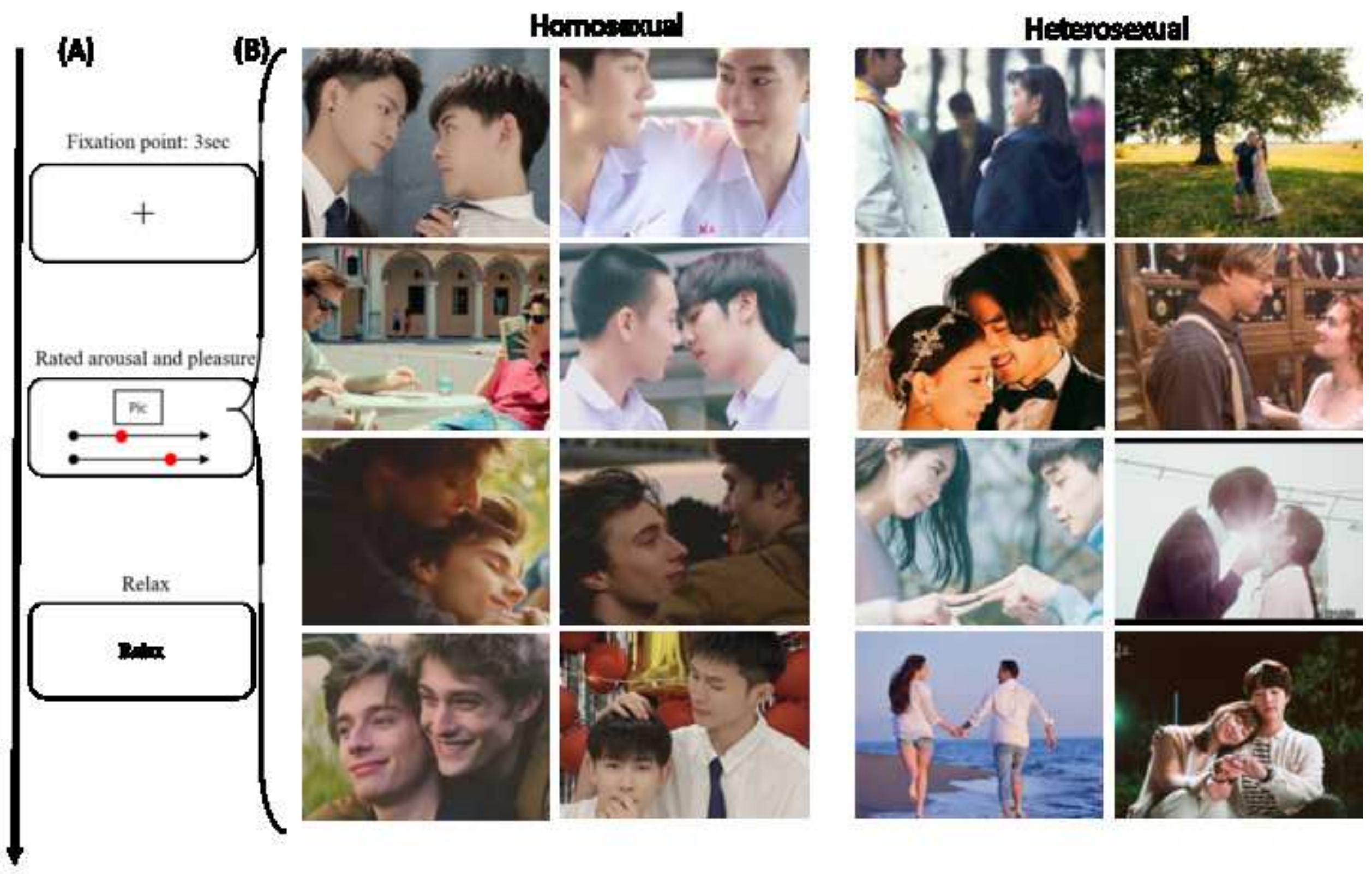



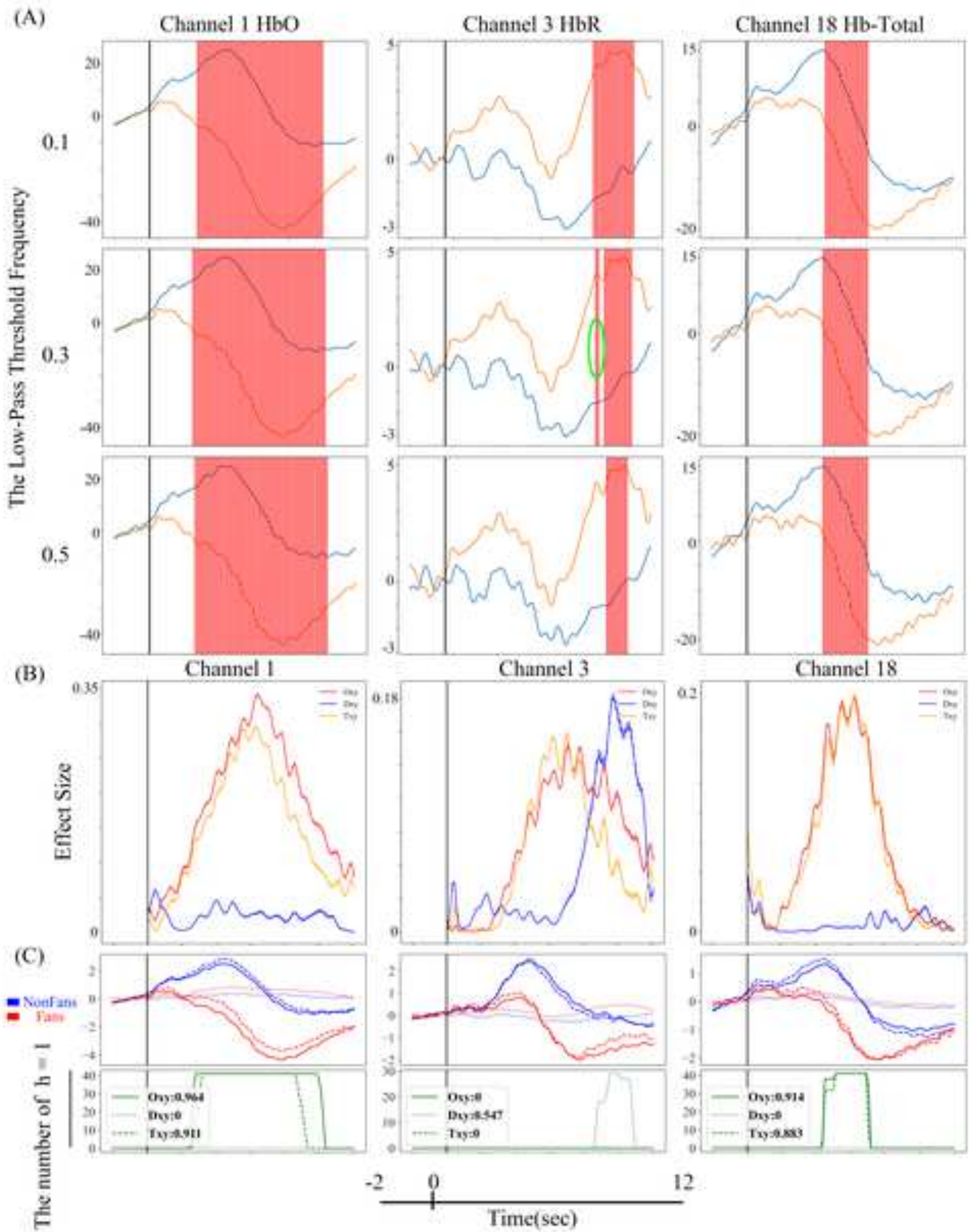

总

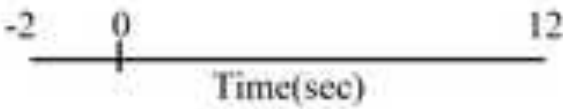

\section{2}

m Nontan:

m tá

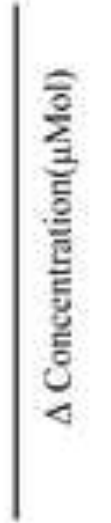


(A) Group Condition in Channel 1

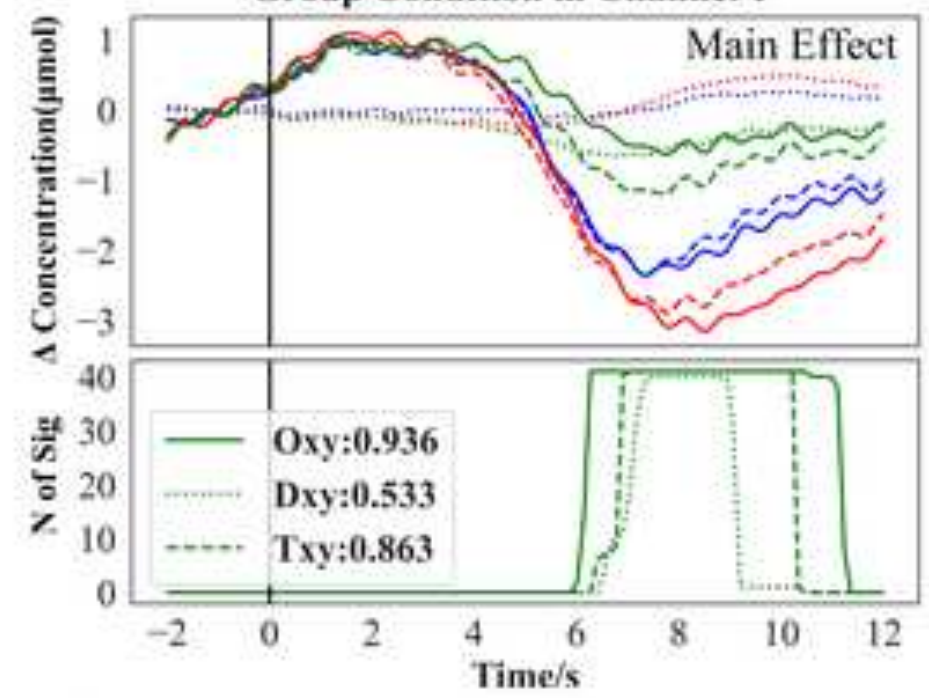

(B)

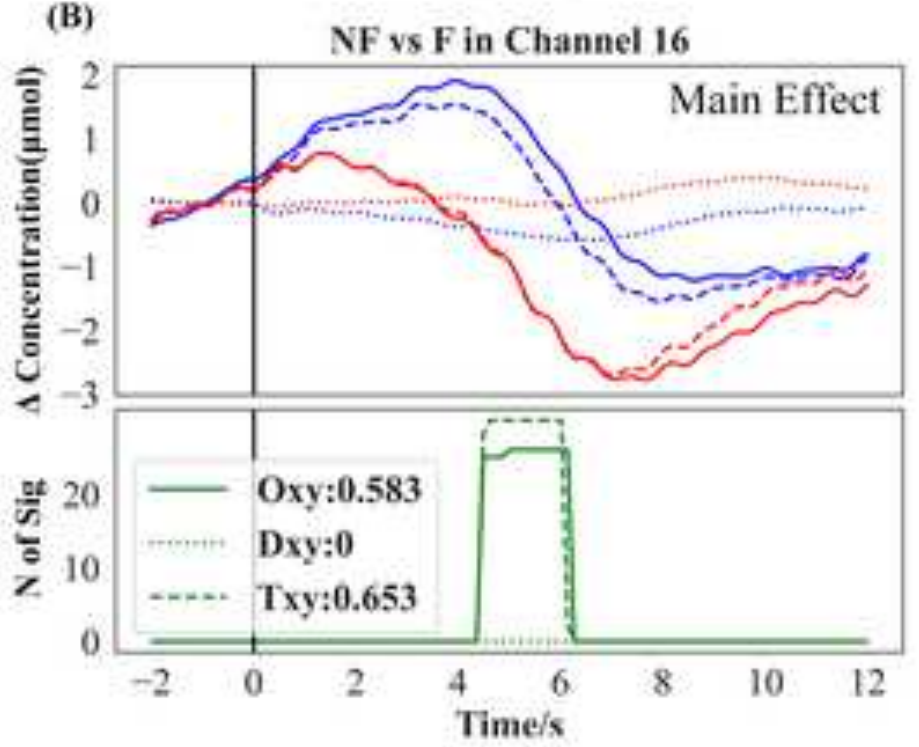

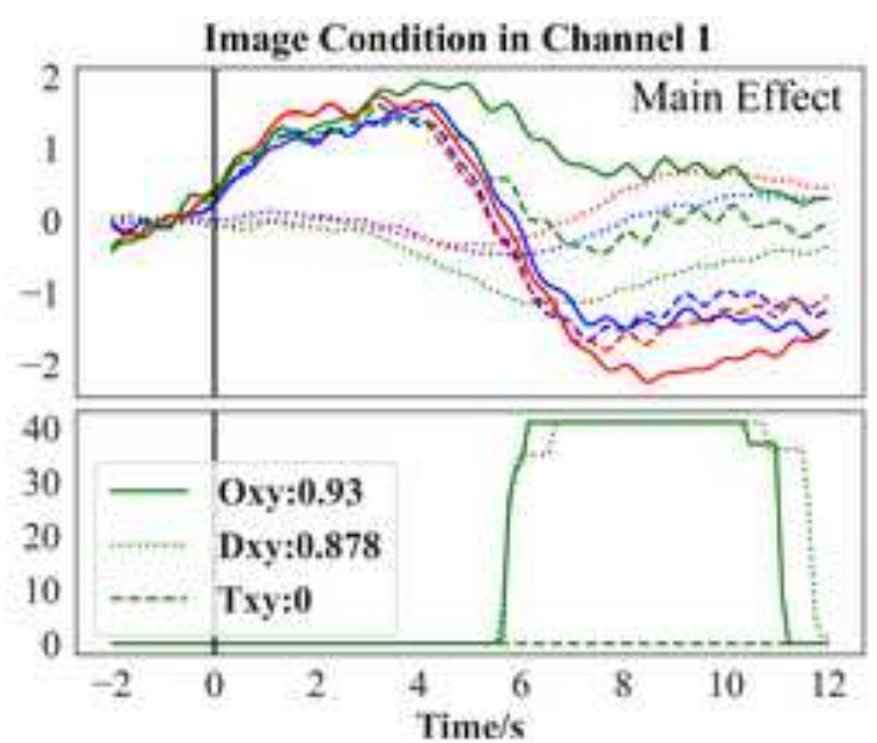

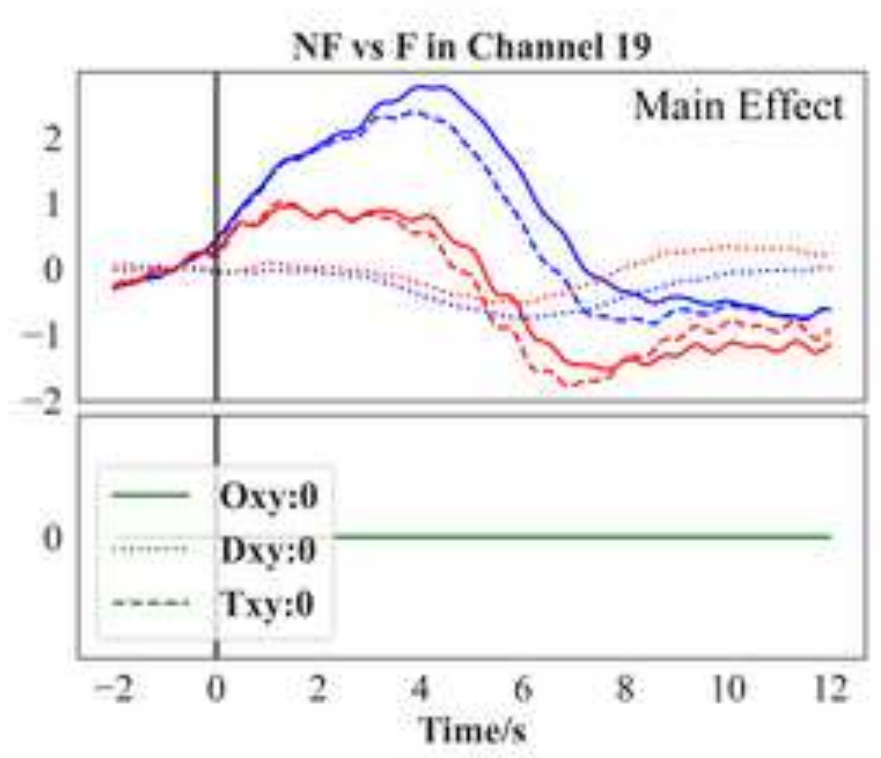

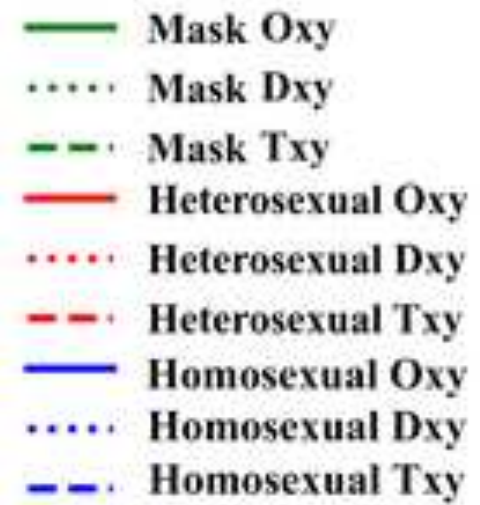

- Mask Oxy

- - Mask Txy

- Heterosexual Oxy

Heterosexual Dxy

sexual Txy

Homosexual Txy 

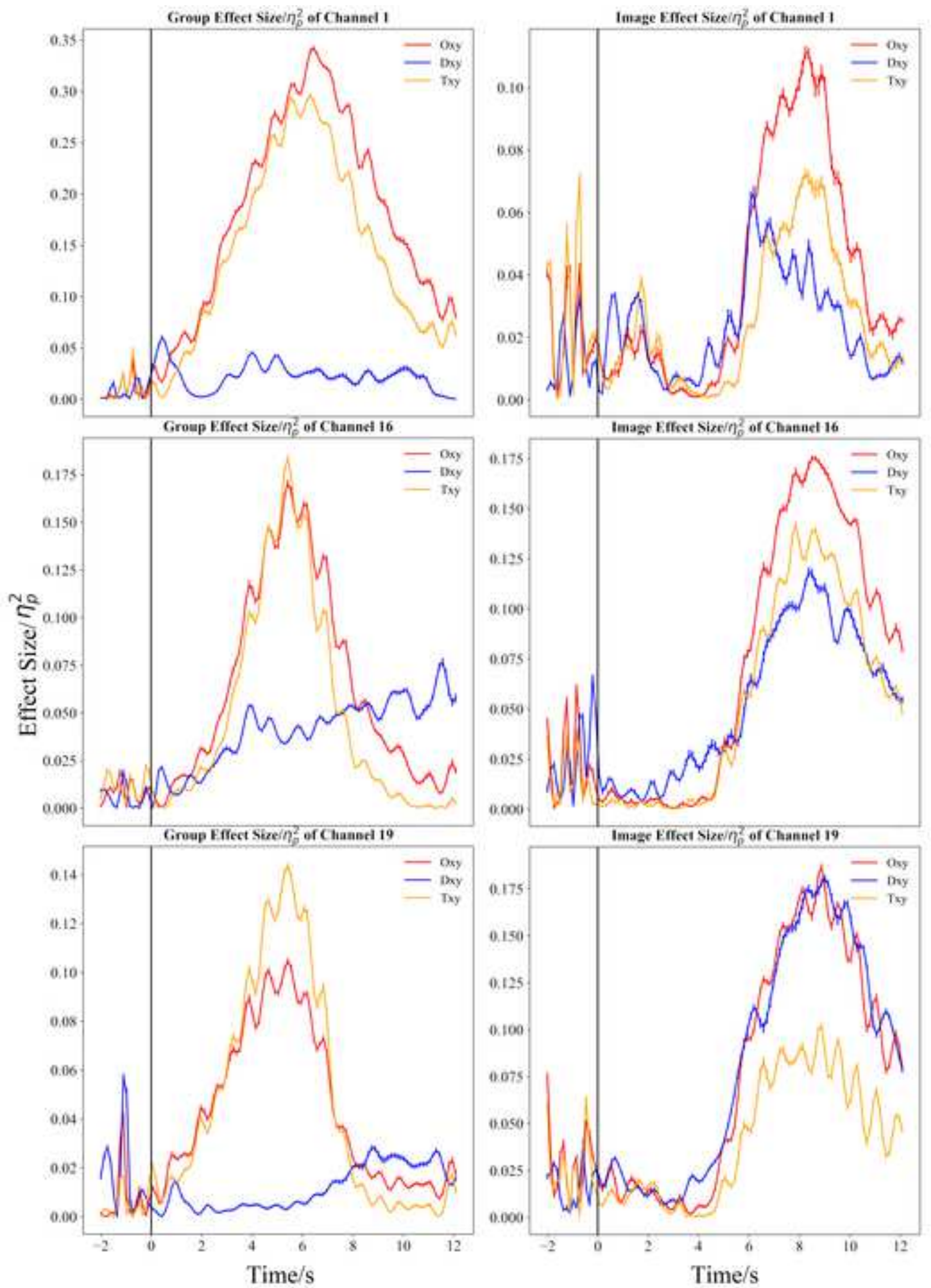


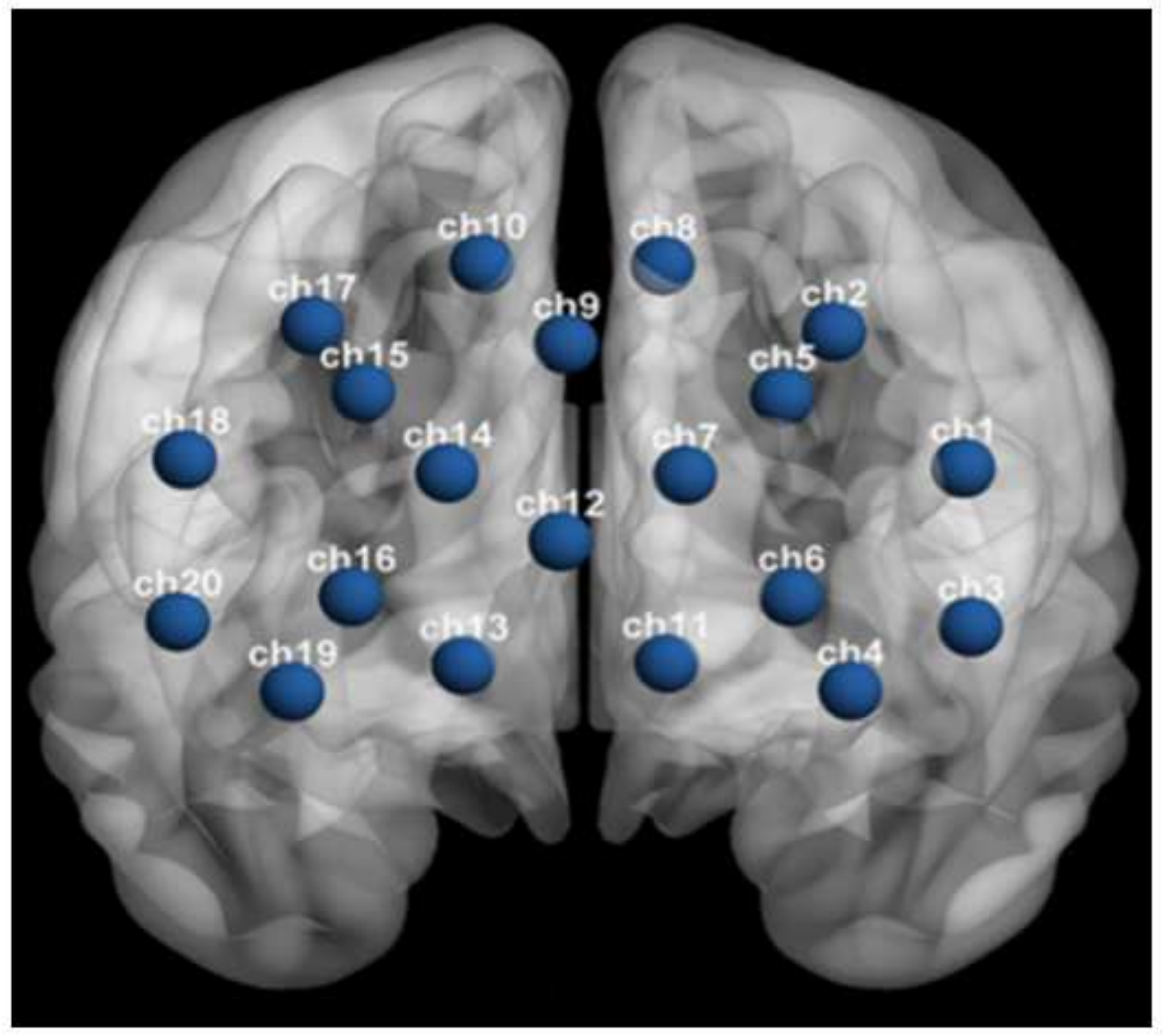


Click here to access/download

\section{Supplementary Material Sup-.docx}

